\title{
Gaining and sustaining 'hospitable' employment for disability youth
}

\section{Richard Robinson}

\author{
Dr Richard N.S. Robinson is \\ Research Development \\ Fellow, UQ Business School, \\ The University of \\ Queensland. Richard \\ practiced as a chef before \\ joining The University of \\ Queensland in 2005. His \\ research projects, often \\ nationally and \\ internationally funded, \\ explore tourism and \\ hospitality workforce policy \\ and planning, skills \\ development, identifying \\ 'foodies' consumer \\ behaviours and designing \\ and evaluating education \\ programmes. He holds a \\ UQ Research Development \\ Fellowship to investigate \\ gaining and sustaining \\ employment for \\ disadvantaged youth.
}

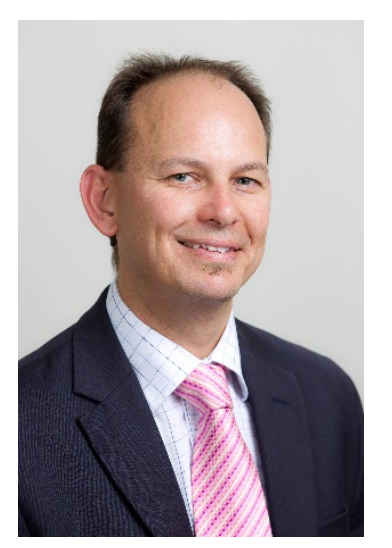

As the hospitality industry globally suffers persistent skills shortages, organisations are increasingly looking to non-traditional labour markets to fill vacancies. Indeed, hospitality has a long tradition of employing from society's margins [1]. Research has shown hospitality firms are more likely than other industries to hire people experiencing disability [2]. Therefore, hospitality has the need, the tradition and the capacity to implement and support lasting change in the employment of disability youth.

The Australian National Disability Insurance Scheme (NDIS), which is overhauling the sector and transforming the way persons experiencing disability access services, is modelled on research demonstrating the broader economic benefits of greater inclusive workforce participation [3]. The scheme is also consistent with the fact that employment is the key to exits from disadvantage for most people of working age [4]. Yet Australia ranks 21st out of 29 OECD nations in disability employment rates [5]. These poor rates of providing inclusive employment are often levelled at firms' unwillingness to hire applicants with a disability [6].

In late 2016, a disability services provider (DSP) and a registered charity partnered in a mobile coffee cart social enterprise to create open employment pathways for a group of disability youth previously employed in the 'sheltered workshop' model. A 360-degree ethnography combining interview and observational methods [7] was designed to investigate the holistic experiences of the youth and to gain insights into the levers and barriers regarding open employment. The agency/structure dualism framed the study, as it is recognised that agency is in itself not sufficient when its expression is constrained by an individual's social deficits and the legacies of their entrenched disadvantage [8]. In all, five 'baristas' experiencing disability (across 10 interviews), 11 coworkers/managers from the DSP and the charity, and 21 customers comprised the sample.

Previous research has identified industry's reticence to employ people with disability as a key barrier, despite ability and willingness to work [5]. This study, however, identified a complex range of structural factors inhibiting the agency of disability youth to self-determine towards open employment. These included a history of poor experiences in institutional settings (e.g. schooling and sporting), the safety and security of sheltered workshops, parental oversight and the staffing requirements of DSP social enterprises. Surprising individual-level factors were also manifest, including the inability to responsibly manage new- 
found workplace independence and an absence of extrinsic motivators to work - given that the disability youth enjoyed financial security regardless of earnings.

This research challenges the conventional wisdom that organisations alone need to revisit their willingness, capacity and preparedness for providing accessible employment, and rather suggests that deep-seated structural factors, and their impacts on youth, require concomitant attention.

\section{Corresponding author}

Richard Robinson can be contacted at: richard.robinson@uq.edu.au

\section{References}

(1) Baum, T. Human Resources in Tourism: Still Waiting for Change? A 2015 Reprise. Tourism Management 2015, 50, 204-212.

(2) Houtenville, A.; Kalargyrou, V. Employers' Perspectives about Employing People with Disabilities. Cornell Hospitality Quarterly 2014, 56(2), 168-179.

(3) Deloitte Access Economics. The Economic Benefits of Increasing Employment for People with Disability; Australian Network on Disability: Sydney, Australia, 2011.

(4) McLachlan, R.; Gilfillan, G.; Gordon, J. Deep and Persistent Disadvantage in Australia; Productivity Commission Staff Working Paper: Canberra, Australia, 2013.

(5) Darcy, S.A.; Taylor, T.; Green, J. 'But I Can Do the Job': Examining Disability Employment Practice through Human Rights Complaint Cases. Disability and Society 2016, 31(9), 1242-1274.

(6) Lysaght, R.; Cobigo, V.; Hamilton, K. Inclusion as a Focus of Employment-Related Research in Intellectual Disability from 2000 to 2010: A Scoping Review. Disability and Rehabilitation 2012, 34(16), 1339-1350.

(7) Sandiford, P. Participant Observation as Ethnography or Ethnography as Participant Observation in Organizational Research. In The Palgrave Handbook of Research Design in Business and Management; Strand K. (Ed.); Palgrave Macmillan: London, 2015; pp 411-446.

(8) Graham, J.; Shier, M.; Eisenstat, M. Young Adult Social Networks and Labour Market Attachment. Journal of Social Policy 2015, 44(4), 769-786. 